\title{
Association of Interferon-gamma gene polymorphism (+874 T/A) with systemic sclerosis
}

\author{
Isabela J. Wastowski ${ }^{\mathrm{a}, \mathrm{c}, *}$, Percival D. Sampaio-Barros ${ }^{\mathrm{b}, \mathrm{d}}$, Gustavo Martelli-Palomino $^{\mathrm{a}}$, \\ João Francisco Marques-Neto ${ }^{\mathrm{b}}$, Janaina C.O. Crispim ${ }^{\mathrm{a}}$, Diane M. Rassi ${ }^{\mathrm{a}}$ and Eduardo A. Donadi ${ }^{\mathrm{a}}$ \\ ${ }^{a}$ Program of Basic and Applied Immunology, Faculty of Medicine of Ribeirão Preto, University of São Paulo, Brazil \\ ${ }^{\mathrm{b}}$ Unit of Rheumatology, Department of Internal Medicine, Faculty of Medical Sciences, State University of \\ Campinas, Campinas, Brazil \\ ${ }^{\mathrm{c}}$ Master's Program in Genetics, Pontifical Catholic University of Goiás, Goiânia, Brazil \\ ${ }^{\mathrm{d}}$ Division of Rheumatology, University of São Paulo, São Paulo, Brazil
}

\section{Introduction}

Systemic sclerosis (SSc) is a connective tissue disease characterized by abnormalities of three systems (immune, vascular, and mesenchymal extracellular matrix), leading to fibrosis development. Raynaud's phenomenon is usually the first symptom, which is associated with a diffuse small vessel vasculopathy and ischaemia as well as reperfusion injury to skin and organs targeted in this disease. The interaction of immune cells with vascular endothelium, through adhesion molecules and the effect of cytokines, is one of the earlier changes in SSc [1]. Dermal mononuclear cell infiltrates in SSc have been shown to be both CD4 and CD8 activated lymphocytes [2]. The migration of mononuclear cells in the perivascular space and the release of cytokines are responsible for fibroblast activation, excessive collagen and glucosaminoglycan production. Several cytokines that may contribute to the worsening of the disease have been found in the sera and BALF of patients with active disease [3]. Peripheral blood mononuclear cells obtained from SSc patients show spontaneous in vitro release of the 'fibrogenic' cytokines tumour necrosis factor (TNF) and IL-1b, and an impairment of mitogen-induced IFN- $\gamma$ production [4].

\footnotetext{
* Corresponding author: Isabela Jubé Wastowski, Program of Basic and Applied Immunology. Faculty of Medicine of Ribeirão Preto, University of São Paulo. Av. Bandeirantes, 3900, 14049-900 Ribeirão Preto, SP, Brazil. Tel.: +55 16 36023373; Fax: +55 16 36336695; E-mail: wastowski@usp.br.
}

IFN- $\gamma$ is the most potent stimulator of HLA class II antigens on endothelial cells, up-regulating endothelial - leucocyte adhesion; however, it is also a negative regulator of collagen production by fibroblasts [5].

INF- $\gamma$ plays a key role in controlling immune response and inflammation, and some polymorphic sites distributed along coding and non-coding regions have been associated with INF- $\gamma$ production. The first reported polymorphic site describes a short-tandem CA repeat in the first intron of INF- $\gamma$ gene, characterizing a $12 \mathrm{CA}$ repeat, named allele 2 , associated with high production of INF- $\gamma$ [6]. Next, a single nucleotide polymorphism $+874^{*} \mathrm{~T} / \mathrm{A}$, at the 5 ' end of the CA repeat region in the first intron was described. Considering the linkage disequilibrium of the $\mathrm{T}$ allele with the allele 2 microsatellite, and considering that the $\mathrm{T}$ to $\mathrm{A}$ polymorphism coincides with a putative NF-kappa B binding site, an association with high transcription of INF- $\gamma$ was reported [7].

Since INF- $\gamma$ has a key role in SSc pathogenesis and there is no report of the association between +874 A/T SNP and SSc susceptibility, we investigated the frequency of INF- $\gamma+874$ polymorphism in a series of Brazilian SSc patients.

\section{Patients and methods}

\subsection{Patients}

DNA samples were obtained from 177 SSc patients (156 females) followed at the Faculty of Medical Sci- 


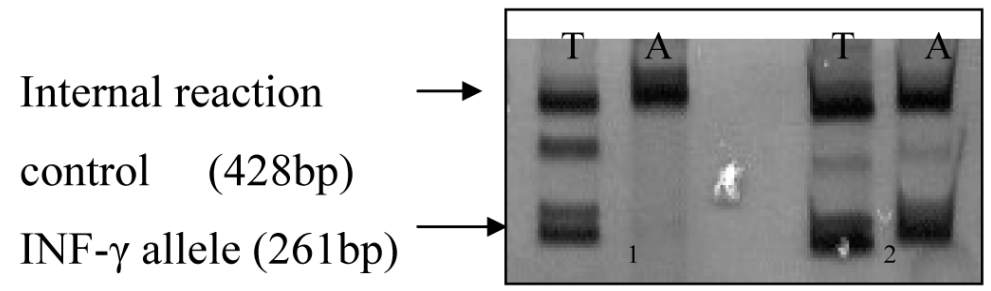

Fig. 1. Gel electrophoretic analysis of $+874 \mathrm{INF}-\gamma$ polymorphism $(261 \mathrm{bp})$. The PCR products were obtained from two different donors. (1) Homozygous donnor TT; (2) Heterozygous donnor TA. Primers for human growth hormone gene (428 bp fragment) were used as internal reaction control.

ences, State University of Campinas, UNICAMP, SP, Brazil. All patients fulfilled the American College of Rheumatology classification criteria for SSc [8], and were divided into diffuse and limited SSc according to LeRoy et al. [9]. Hundred nine patients presented limited SSc (100 women) and 68 patients (56 women) presented diffused SSc. All the patients were clinically evaluated based on a standard protocol of investigation of SSc patients of the Unit of Rheumatology of UNICAMP. The extension and severity of skin thickening was evaluated by the modified Rodnan skin score (mRSS) that analyzes 17 anatomical sites, graded from 0 (normal skin) to 3 (intense skin thickening). Esophageal motility, chest radiography, lung functional tests, pulmonary artery systolic pressure and doppler echocardiogram were routinely performed in all patients.

A total of 191 unrelated healthy bone marrow donors (160 females) were also studied. The study protocol was approved by the local Ethics Committee (protocol \# 9581/2002).

INF- $\gamma+874$ polymorphism was identified using PCR-amplified DNA hybridized with sequence-specific primers, as described by Pravica et al., identifying a 261 bp fragment [7]. Primers for human growth hormone gene (428 bp fragment) were used as internal reaction control (Fig. 1).

\section{Statistical analysis}

The Hardy - Weinberg equilibrium (HWE) was determined by Pearson's $\chi 2$ goodness-of-fit test. Allele and genotype frequencies were compared between groups using the Fisher's exact test. A p value $\leqslant 0.05$ was considered to be significant. Odds ratios (OR) with 95\% confidence interval $(\mathrm{CI})$ were calculated using the statistical program GraphPad Instat.
Table 1

Genotype and allele frequencies for the +874 at the first intron of the INF- $\gamma$ gene in healthy controls and SSc patients

\begin{tabular}{|c|c|c|c|}
\hline & $\begin{array}{l}\text { Controls } \\
(n=191)\end{array}$ & $\begin{array}{c}\text { SSc limited } \\
\text { patients } \\
(n=109)\end{array}$ & $\begin{array}{c}\text { SSc diffused } \\
\text { patients } \\
(n=68)\end{array}$ \\
\hline \multicolumn{4}{|c|}{ Genotype frequencies } \\
\hline $\mathrm{A} / \mathrm{A}$ & $60(31 \%)$ & $40(37 \%)$ & $32(47 \%)$ \\
\hline $\mathrm{T} / \mathrm{T}$ & $34(18 \%)$ & $32(29 \%)$ & $7(10 \%)$ \\
\hline $\mathrm{T} / \mathrm{A}$ & $97(51 \%)$ & $37(34 \%)$ & $29(43 \%)$ \\
\hline \multicolumn{4}{|c|}{ Allele frequencies } \\
\hline A & $214(56 \%)$ & $116(54 \%)$ & $92(68 \%)$ \\
\hline $\mathrm{T}$ & $168(44 \%)$ & $100(46 \%)$ & $44(32 \%)$ \\
\hline
\end{tabular}

\section{Results}

Genotype and allele frequencies for the +874 INF$\gamma$ polymorphism in patients and controls are shown in Table 1. Genotype frequencies of healthy individuals and patients were in accordance with HWE. The +874 A allele was overrepresented in patients presenting Rodman modified skin score greater than $12(p=$ $0.034, O R=1.5795 \%$ IC: $1.044-2.360)$. The A/A genotype was also associated with reduced $(\leqslant 70 \%)$ vital force capacity $(P=0,01, O R=1,79 ; 95 \%$ IC: 1,235-2,562).

When patients were compared according to SSc clinical variants, the T/T genotype was significantly increased in patients presenting limited SSc $(P=0,002$; $O R=0,27 ; 95 \%$ IC: $0,1140-0,6686)$. Compared to non-Caucasians, the T/T genotype was significantly increased in Caucasians, irrespective of the disease variant $(P=0,009 ; O R=0,8 ; 95 \% \mathrm{IC}: 0,6976-0,9207)$.

\section{Discussion}

IFN- $\gamma$ exhibits inhibitory effects on collagen synthesis, being considered an immunomodulatory cytokine in SSc, especially in early stages of the disease [3,10]. Both serum levels and peripheral blood mononuclear 
Table 2

Genotype and allele frequencies for the +874 at the first intron of the INF- $\gamma$ gene in clinical manifestations that presented allelic or genotypic significant differentiation

\begin{tabular}{cccc}
\hline & $1(n=69)$ & $2(n=34)$ & 3 Caucasian/AB \\
\hline \multicolumn{4}{c}{ Genotype frequencies } \\
A/A & $34(49 \%)$ & $19(56 \%)$ & $50(28 \%) / 19(11 \%)$ \\
T/T & $11(16 \%)$ & $6(18 \%)$ & $48(27 \%) / 5(3 \%)$ \\
T/A & $24(35 \%)$ & $9(26 \%)$ & $40(23 \%) / 15(8 \%)$ \\
\multicolumn{4}{c}{ Allele frequencies } \\
$\mathrm{A}$ & $92(67 \%)$ & $47(72 \%)$ & $140(39 \%) / 53(15 \%)$ \\
$\mathrm{T}$ & $46(33 \%)$ & $18(28 \%)$ & $136(38 \%) / 25(8 \%)$ \\
\hline
\end{tabular}

(1) Patients presenting Rodman modified skin score greater than 12 ( $p=0.034, O R=1.5795 \%$ IC: $1.044-2.360)$. (2) Patients presenting reduced $(\leqslant 70 \%)$ vital force capacity ( $P=0,01, O R=1,79 ; 95 \%$ IC: $1,235-2,562)$. (3) Race (Caucasian/African-Brazilians)- $(P=0,009 ; O R=0,8$; 95\%IC: 0,6976-0,9207).

cell IFN- $\gamma$ production are described to be decreased in SSc patients with clinically active disease compared to stable disease, suggesting that high levels of IFN- $\gamma$ may play a protective role in clinically stable patients [11].

In the present study, the IFN- $\gamma$ T/T genotype, which has been associated with high levels of cytokine production, was also associated with the limited SSc variant, particularly among Caucasians, in whom the disease has a better clinical evolution [8]. Although no study on IFN- $\gamma$ polymorphism has been reported for $\mathrm{SSc}$, the $+874 \mathrm{~A} / \mathrm{A}$ genotype has been associated with the presence of arthritis in systemic lupus erythematosus patients [12].

Our results suggest that the genotype T/T could be associated with the better prognostic of SSc, because this polymorphism seems to favor the INF- $\gamma$ gene transcription and consequently the higher production of the cytokine, which has immunomodulatory effect in collagen production.

$\mathrm{SSc}$ is a complex disease and several genes may contribute to its pathogenesis. Ours results support that genetic variation in the IFN- $\gamma$ gene might influence the disease course of SSc.

\section{Financial support}

Coordenação de Aperfeiçoamento de Pessoal de Nível Superior (CAPES) and Conselho Nacional de Desenvolvimento Científico e Tecnológico (CNPq).

\section{References}

[1] E.C. LeRoy, A brief overview of the pathogenesis of scleroderma (systemic sclerosis), Ann Rheum Dis 51 (1992), 286288.

[2] C. Mauch, B. Eckes, N. Hunzelmann, T. Oono, E. Kozlowska and T. Krieg, Control of fibrosis in systemic scleroderma, $J$ Invest Dermatol 100 (1993), 92-96.

[3] M.R. Duncan and B. Berman, Persistence of a reducedcollagen- producing phenotype in cultured scleroderma fibroblasts after short term exposure to interferons, J Clin Invest 79 (1987), 1318-1324.

[4] A.S. Narayanan, J. Whithey, A. Souza and G. Raghu, Effect of g-interferon on collagen synthesis by normal and fibrotic human lung fibroblasts, Chest 101 (1992), 1326-1331.

[5] R.P. Polisson, G.S. Gilkeson, E.H. Pyun, D.S. Pisetsky, E.A. Smith and L.S. Simon, A multicenter trial of recombinant human IFN-g in patients with systemic sclerosis: effects on cutaneous fibrosis and interleukin 2 receptor levels, J Rheumatol 23 (1996), 654-658.

[6] V. Pravica, A. Asderakis, C. Perrey et al., In vitro production of IFN-gamma correlates with CA repeat polymorphism in the human IFN-gamma gene, Eur J Immunogenet 26(1) (1999), $1-3$.

[7] V. Pravica, C. Perrey, A. Stevens et al., A single nucleotide polymorphism in the first intron of the human IFN-gamma gene: absolute correlation with a polymorphic CA microsatellite marker of high IFN-gamma production, Hum Immunol 61(9) (2000), 863-866.

[8] A.T. Masi, G.P. Rodan, T.A. Medsger Jr. et al., Preliminary criteria for the classification of systemic sclerosis (scleroderma), Arthritis Rheum 23 (1980), 581-590.

[9] E.C. LeRoy, C. Black, R. Fleischmajer et al, Scleroderma (systemic sclerosis): classification, subsets and pathogenesis, J Rheumatol 15 (1988), 202-205.

[10] S. Romagnani, TH1 and TH2 in human diseases, Clin Immunol Immunopathol 80 (1996), 225-235.

[11] M.I. Molteni, S. Della Bella, B. Mascagni, S. Bazzi, C. Zulian, S. Compasso, M. Lessi and R. Scorza, Increased interferon-gamma (IFN-g) levels produced in vitro by alloactivated T lymphocytes in systemic sclerosis and Raynaud's phenomenon, Clin Exp Immunol 116 (1999), 164-168.

[12] M. Tangwattanachuleeporn, P. Sodsai, Y. Avihingsanon, J. Wongpiyabovorn, J. Wongchinsri and N. Hirankarn, Association of interferon-gamma gene polymorphism $(+874 \mathrm{~A})$ with arthritis manifestation in SLE, Clin Rheumatol 26 (2007), 1921-1924. 


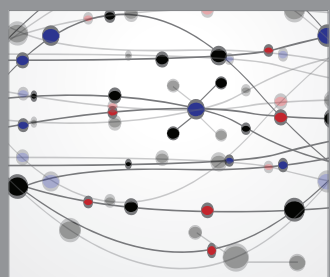

The Scientific World Journal
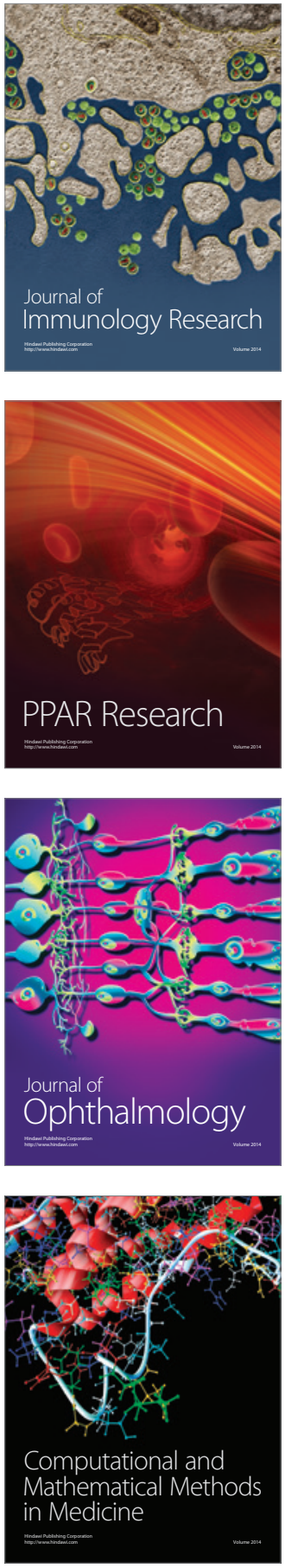

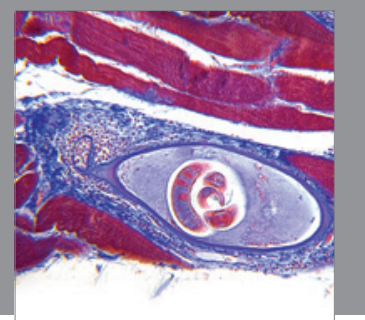

Gastroenterology

Research and Practice
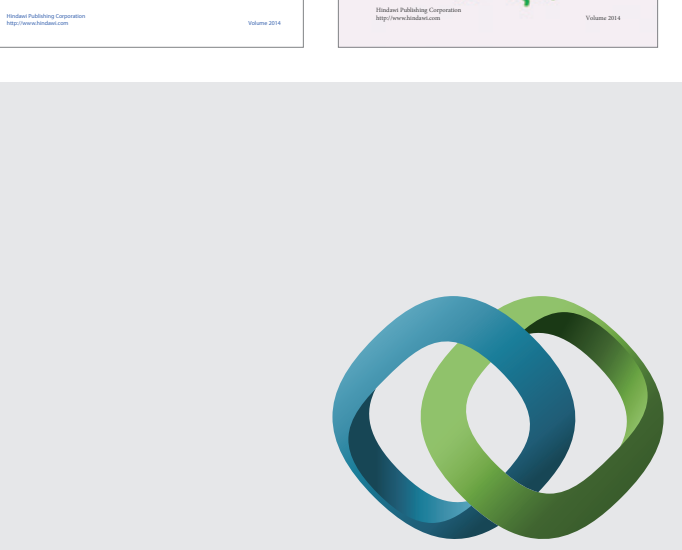

\section{Hindawi}

Submit your manuscripts at

http://www.hindawi.com
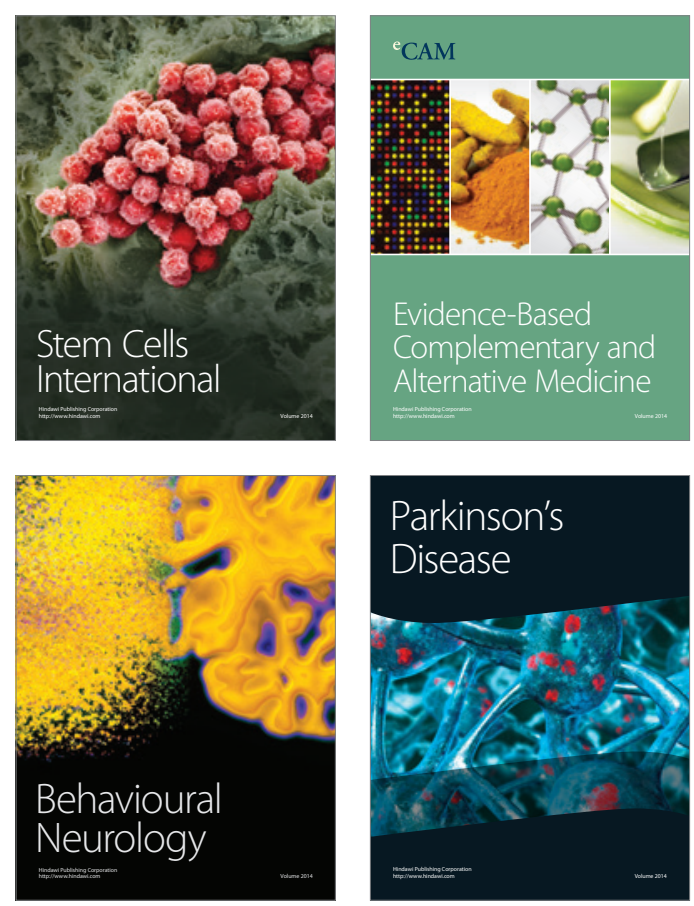

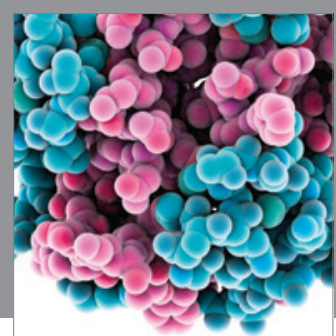

Journal of
Diabetes Research

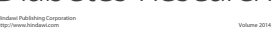

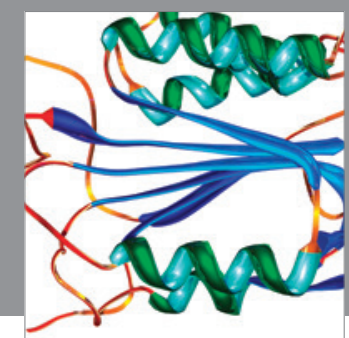

Disease Markers
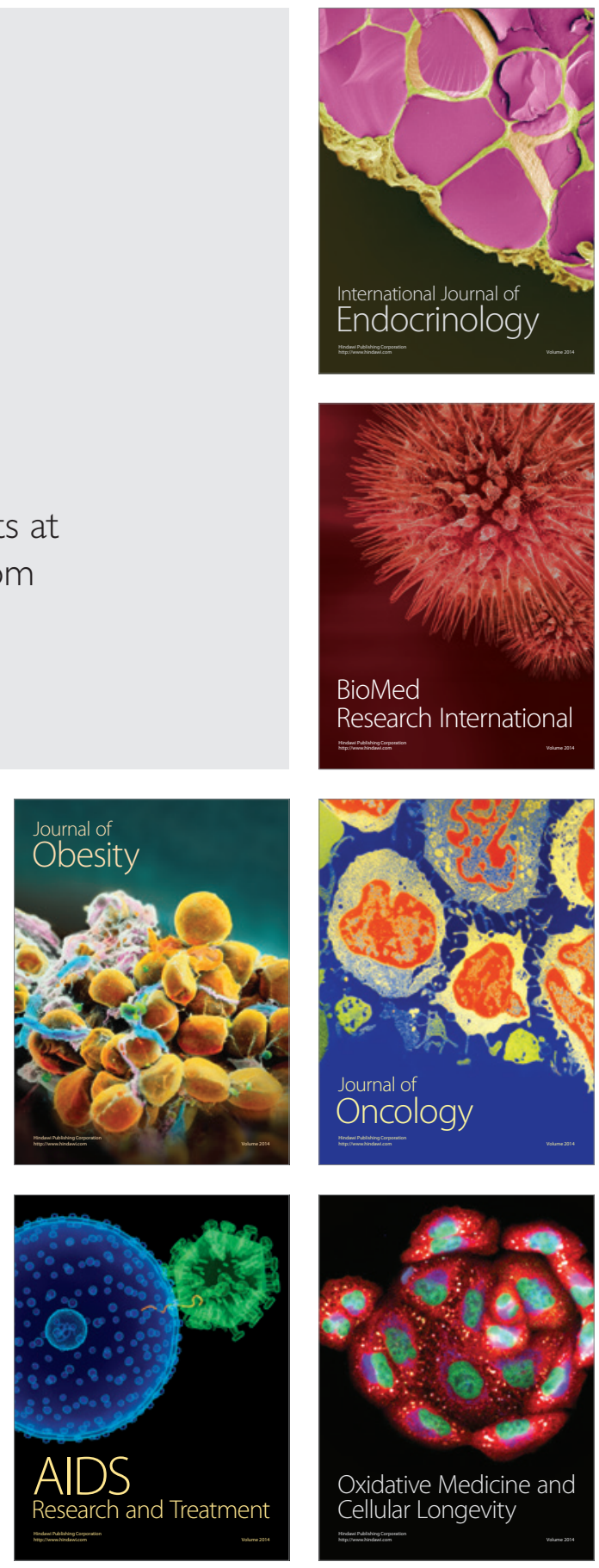